\title{
THE CAMPUS BAR AS A "BASTARD INSTITUTION"
}

\author{
Deborah A. Willsie \\ Syracuse University \\ Jeffrey W. Rierner \\ Wichita State University
}

Mid-American Review of Sociology, 1980, Vol. V, No. 2:61-89

Most college and university campuses in American society have fringe areas adjacent to them that cater to the needs of students and faculty. Here one will often find low rent housing, quick food restaurants, laundromats, food, clothing, and other specialty shops. These fringe areas become a natural extension of the academic institution and help to provide for the academic communities' physiological, psychological, and social needs in areas where the academic institution cannot or does not engage.

Bars, taverns, lounges or pubs are one such private enterprise that caters to the needs of persons of the academic community. These enterprises differ by service provided and type of clientele. Some campus drinking establishments emphasize a recreational atmosphere by providing their patrons an array of machinery that must be continually plugged with coins. Here one finds such attractions as pinball, foosball, pool tables, and various other electronic games. Patrons tend to come alone or in groups (typically all male) and combine their drinking (usually beer) with these various mechanical and electronic pursuits. This variety of campus bar, which is typically frequented by fraternity and sorority types and other undergraduate students, opens for business in the early afternoon.

Other campus drinking establishments provide a setting that is conducive to socializing and "picking up" persons of the opposite (or same) sex. Here one finds low lights, music, and an array of tables, booths, and bar stools. Sometimes referred to as "meatmarket bars" these places structurally facilitate milling and conversation between patrons. Persons tend to come alone, in same sex couples or small groups. Flirtation and conversation are the primary activities that combine with the drinking of alcoholic 
beverages, usually mixed drinks, beer and wine. The clientele typically found in these establishments include both under. graduate and graduate students and occasionally faculty members. This variety of campus bar opens for business in the late afternoon or early evening.

One additional variety of campus drinking establishment can be singled out. Taking Cavan's (1966) lead, the "home territory bar" provides a retreat for a special group from the campus community. The primary activities of these establishments are socialization and conversation among the regulars. Patrons tend to share a common social identity-their college or university afflia. tion and intellectual interests. The more homogeneous the identity of the patrons the more the members may work to exclude outsiders. Regular clientele act as though the establishment belongs to them. They may draw their own beer, borrow money from the till, answer the phone and receive mail and messages at the bar. This variety of campus drinking establishment is typically patronized by a select group of advanced students and some faculty. These bars are often open for business in the late morning.

Of course all campus bars may provide any of the above mentioned features as well as other services provided by other business establishments in the community such as food service. But it is typical to find one service that is emphasized over others and one type of patron that is catered to at the expense of others:

When campus drinking establishments are viewed in a broader environment context, as part of the weave of academic life and lifestyle, they take on an important role in the overall functioning of the academic community. Bars provide opportunities for patrons in sociability, playing, and drinking (Roebuck and Frese, 1976:24). The college or university may not be able to provide these same services to members of the academic community or may not choose to because of moral consequences.

Cavan (1966) suggests that bars have a historical reputation of being of questionable moral worth.

She documents the fact that both the legal statutes governing such settings and the historical characterizations of what goes on in them define these places as 'marginal if not disrespectable.' Bars are risky places where all sorts of untoward, illegal, rowdy, lascivious behavior is likely to occur among intoxicated people. Therefore all sorts of legal proscriptions and prescriptions are attached to the proprietors, employees, and patrons in these settings. Age limitation, license limitation, time and space limitation, beverage and food limitation and behavioral limitation are examples (Roebuck and Frese, 1976:20).

Everett Hughes has suggested the term "bastard institution" for those establishments and enterprises that provide goods or services that are less than legitimate or less than morally acceptable. According to Hughes (1971:99)

Some are the illegitimate distributors of legitimate goods and services; others satisfy wants not considered legitimate. ... Some of these bastard institutions are directly against the law, or declared moral values of society. They are in direct conflict with accepted definitions and institutional mandates. Others offer a less than fully respectable alternative, or allow one to satisfy some hidden weakness or idiosyncratic taste not provided for, and slightly frowned on, by the established distributors. Still others quite simply offer a way to get something not readily available to people of one's kind in the prevailing institutional system. They are corrections of faults in institutional definition and distribution.

Clearly, Hughes is highlighting such enterprises as prostitution, gambling, black markets and the like, that are considered illegal. In this paper we will emphasize the moral and symbolic quality of the concept by focusing on the campus bar as a bastard institution. We will delineate the functions of the campus bar as they relate to campus life and as an extension of the predominant academic institution.

Pointing out the broader social and environmental functions of drinking establishments in American society is not new. Dumont (1967) has focused on the skid row bar, Cavan (1966) has compared types of bars by their special uses-drinking, amusement, 
club and marketplace, Roebuck and Frese (1976) have centered on the after-hours club, Gottlieb (1957) has compared the neighborhood tavern and the cocktail lounge, Macrory (1952) has discussed the tavern in relation to the larger community and Erdoes (1980) has provided a historical view of the functions barrooms provide in his discussion of the saloon of the old west. Our discussion will center primarily on the "home territory" variety of campus bar.

\section{METHOD}

This research was conducted in a campus bar located near a university in a large mid-western city over a period of three years. The first author has patronized this establishment as a regular customer over this period. Observations were made at various times during regular business hours, 10:30 a.m. - 12:00 midnight, Monday through Saturday.

The methodological techniques employed included participant observation supplemented by selective focused interviews during the latter part of the research with the owner, another bartender and patrons. Unobtrusive measures (Webb et al., 1966) were also used to gather physical trace evidence, particularly accretion such as graffiti and the ever changing decor of the bar. The data are reported with an attitude of comparison to other nearby, campus bars which were also visited during the same time period.

This completed research report was shared with the owner/ bartender of the establishment and some selected patrons as a means to access the accuracy of the observations and their pre sentation. We believe this "post observational inquiry" (Denzin, 1970:340) served as an additional means to control the quality of our observations.

\section{THE SETTING}

Although it is located across the street from campus, it is easy to miss, hidden behind shrubbery and overshadowed by the laundromat next door. If anyone asks where it is, the usual answer is "across from (the President's) house."

Once inside the door, the newcomer is astounded by the apparent clutter. But the regular is accustomed to the densely arranged cedar tables and benches, along with the walls which are entirely papered with old photographs and posters. The owner is behind the bar drying just-washed beer glasses and talking to the man and woman seated at the end. A regular is playing the pinball machine as usual and two other men are playing the new electronic space game. The vibrations and rhythm of the record "Eve of Destruction" is coming out of the jukebox, but not so loud that it prevents conversation.

Because of its size the room seems crowded even with thirty people. The tables, which hold from four to six people each, are all full and five people are seated at the bar. One patron is asking the owner for another pitcher, which is the usual order since the establishment is a beer bar with only one kind of beer on tap. Different kinds of canned beer and soft drinks and sometimes coffee are available, but if you are hungry you must settle for potato chips, a hot dog, or "boneless chicken"-a hardboiled egg.

The telephone rings and a regular patron, who happens to be nearest to it because he is playing the jukebox, answers with (the name of the bar). After a slight pause he shouts out a regular's name and a young man gets up and goes over to the phone. The owner calls out "And how are you today, (patron's name)?" as she comes in the door, and after resting her bicycle against the wall and getting a glass, she joins a group already seated in the corner.

The scantily clad female mannequin beside the jukebox has been given a combat helmet by one of the patrons and some new snapshots have been added to one wall, but the inside looks almost as it has for the last few years. Somewhat recent additions are the signs on the restroom doors designating men and women (a poster of Judy Garland on one door had previously been the only distinguishing feature).

The owner is walking around now, picking up dirty glasses and emptying ash trays, so a regular patron goes behind the bar 
and gets another pitcher for himself. A couple enters who have obviously not been here before. They walk hesitantly to the bar, taking in everything and staring at the ceiling, which is decorated like the walls. They are given prompt service like everyone else, but no one pays much attention to them after that.

The owner is telling the man and woman at the bar about the next trivia contest, which is being held in a couple of weeks. This is just one of several events which the bar hosts for its patrons. A Halloween party is held every year, where approximately 150 people in complete costume crowd inside and outside the bar and drink free beer as long as the three free kegs last. An annual "End-of-Summer Get Together and Be Someone Party" meets in a nearby park during September to play softball, throw frisbees, and drink more free beer. Old films and home movies are often shown on the screen which pulls down over one wall, and live entertainment is provided for by donations, two or three nights a week.

A female patron comes out of the restroom and walks behind the bar to get a roll of toilet paper off the shelf, the same shelf which holds the trivia library. Now "Eight Miles High" is playing on the jukebox, one of several indicators of the type of clientele which frequents the bar. The patrons are somewhat older than the typical students, usually in their late twenties or early thirties, and might be classified as former, current, or aspiring campus liberals. Almost all are affiliated with the university, either as students, former students, or professors. Two men at the bar are debating the exact location of a small town, so the owner pulls down a map of the state, which is one of several maps on rollers behind the bar.

There is a pervasive friendly feeling in the bar, a contrast to the atmosphere of sexual tension which exists at most campus bars. There is little "pick-up" activity; in fact, women are likely to hug other women and all kinds of people readily talk and sit together.

At five minutes before midnight the owner yells "Last call!" and then goes from table to table passing out paper cups for the unfinished pitchers of beer. The outside lights are turned off, and by $12: 15$ he is alone inside, cleaning up.

\section{SOCIAL FUNCTIONS OF THE CAMPUS BAR}

The "home territory" campus bar exists near most colleges and universities large enough to support various types of drinking establishments. Many of the social functions provided are unique to this type of bar and are related to the needs of the academic community. Seven primary social functions have been isolated from observations and interviews. These include: the provision of goods, services, entertainment, education-orientation, sociation, support group, and sanctuary. All campus bars provide some of these functions but the "home territory" establishment offers a more elaborate and intimate social network

\section{Goods}

The "home territory" campus bar provides its patrons four main tangible goods: drink, food, drugs, and loans. The first two can be considered legitimate goods provided to all patrons whereas, the latter two are provided to select clientele and require special conditions.

Drink

The apparent reason to patronize a campus bar, or any bar, is to drink some alcoholic beverage, whether it is beer, wine, or a mixed drink. Most patrons drink something, either an alcoholic or non-alcoholic beverage. Patrons legitimize their presence as long as drinks continue to be purchased.

This "home territory" bar serves one kind of beer on draft (Cocrs),-various kinds-of canned and bottled beer; several kinds of canned soft drinks, and coffee. The most common order at the bar is, "Can 1 have a draw?" or "Give me a pitcher." Some patrons are "regulars," who always order soft drinks. This indicates that some patrons come to the bar primarily to socialize. For example, coffee is always available in the morning and early afternoon for those who choose to retreat from the campus for some conversation among friends.

The informality of purchase is also displayed here. Patrons, especially "regulars," may serve themselves or draw beers for 
others when the bartender is busy or temporarily away from the bar. This activity includes depositing the payment in the cash register.

Beer, soft drinks, and coffee are also sold on the university campus but the nature of these establishments encourage formality and discourage the comfortable social aspects provided by the "home territory" bar.

Food

A secondary and related function of many drinking establish. ments is the provision of food. The "home territory" bar provides various snack foods-pretzels, potato chips and nuts. For those patrons seeking more nourishment, the options include "boneless chicken" or one of the hot dogs that continue to roll on the mechanized heating unit in back of the bar. When one patron was asked if he had ever had a hot dog in the bar he responded, "Yeah, they're not too bad but I wouldn't really recommend one-I think the ones on there are pretty old."

On Saturdays, around noon a free lunch is sometimes of fered. It consists of soup cooked in a large army kettle by one of the regulars with ingredients provided by the owner. Because of the limited space and customer preference the food menu remains simple. Other nearby food facilities, both on and off campus, attract those persons who are primarily hungry.

\section{Drugs}

A less legitimate but still integral provision of goods is the use, sale, and exchange of illicit drugs. The bartender is never directly invilued in these transactions but some patrons regularly engage in drug transactions on or very near the premises and drug use occurs adjacent to the bar. Few patrons frequent the establishment for this sole purpose, but it is definitely a determinant for some. During warm weather, the adjacent gravel parking lot serves as a gathering place to "smoke a joint."

While inside the bar, one female regular said to the rest of the group seated at her table "It's really hot in here today. Anyone want to go outside?" It was not unbearable hot, and the others knew this was probably a signal to go outside and "get high." The owner allows pitchers and glasses to be taken outside, so everything was moved to the parking lot. The lot is obscured by cars and bushes so detection is unlikely. The female regular began rolling a joint and one man went to his car for a pipe. As both were passed among the group, another man asked, gesturing to the joint, "Is there much of this around right now?" The woman answered, "Yeah, my brother's friend just came back (from Texas) with a whole lot of it. You want some?" The man did and said he would pick it up the next time he dropped by her house.

During colder weather, the intentions inside the bar are sometimes more direct, as one man asks the others at the table, "Does anyone want to go smoke a joint?" But more often one or two people will get up and start putting on their coats. Someone will ask "Oh, are you leaving?" and one answers, "No, we're just going out for a while. Anyone want to come?" They will then sit in their parked cars or drive around the neighborhood. Plans concerning drugs are not loudly advertized, but no extreme effort is made to keep them secret either. None of the regulars would mind, but the bartender appreciates some amount of caution in case a stranger or the police should drop in.

Loans

Tabs and, less commonly, loans are afforded primarily to regulars or those who demonstrate a real need and definite intention to pay later. This service is not advertized, but occasionally a customer will say "Just put it on my tab" and the bartender writes the amount down on a small piece of paper next to the cash register. The tab privilege is apparently not abused by the patrons as no complaints were voiced. One man at the end of the bar was heard shouting, "Hey, when you get a chance, would you figure out my tab?"

Loans are more rare but not unusual. One woman who frequents the bar found her money missing from her purse when she returned from the restroom. She lived out of town and needed to buy gas to get home. She reported the loss to the bartender, who took some money from the cash register, saying, "This ought to get you home, you can bring it back the next time you come 
in." Loans and tabs are usually repaid-to do otherwise in a "home territory" bar would be like stealing from one's family.

\section{Services}

In addition to tangible goods like beer, snacks, drugs, and loans, certain services are also available to patrons in a "home territory" bar. The extent of these services is dependent upon the status of the patron (from stranger to regular), the particular bartender working at the time, the number of people in the bar, and related social conditions. The establishment functions as a message center for its patrons, keeping them informed about bar and school-related activities and about each other. The telephone is another source of both incoming and outgoing information and is utilized by the bartender and customers alike. The bar serves also as a counseling center, on a bartender-to-customer or customer-to-customer basis.

Messages

The bar's function as a message center is readily apparent upon entering. The walls are papered with all kinds of posters, photographs, political statements, business cards, etc. Patrons can add almost anything to the walls and ceiling of the establishment. The management, of course, has the option of forbidding certain additions or removing them. The decorations are historical reminders of past political events, old movies, and former customers. The walls advertise current events, such as the next movie playing on campus or the next trivia contest sponsored by the bar. There are new political additions, showing concern of the mounting Iranian tension: a newspaper picture of the Ayatollah Khomeini has been pasted on a poster next to Hitler and Stalin. and another poster has been altered to read "The U.S. Marines are coming to devour the Iranians."

The bathroom graffiti is a branch of the message center. It contains the usual sexual poems and statements, but also has remarks about specific regulars and quotations from respected authors and songwriters. These latter two components are perhaps unique to this "home territory" campus bar.
The telephone is another source of messages. There is only one phone, a pay phone located at the end of the bar making it accessible to both the bartender and the patrons. It is customary for the person closest to answer it, usually a regular at the bar. If the caller wants to speak with a customer, the regular shouts, "Is (customer's name) here?" Usually the customer is there to take the call because patrons tend to stop here regularly, such as every Friday afternoon or every evening, and their friends know this and know where to find them.

Other messages are relayed simply by people talking to one another. Customers often know many of those in the bar at any time, or they know someone who knows someone. Messages such as, "Tell Joe we went to Jim's party if he comes in," can be left with the bartender or anyone else who knows Joe.

\section{Counseling}

Although the university has formal counseling services, the bar meets a different need for those who want either a friend's advice or just want to talk to someone. In the early afternoon or other "dead" times, the few who come in are often alone and sit at the bar, talking to the bartender and each other. This is one of the times when specific issues are often discussed, such as an impending war, jobs, marriage, or just getting through another day. The bartender is often a moderator in these interchanges. The following conversation from the field notes illustrates this point.

Bartender: Well, we'll let you live your life the way you want oman: That's what I need-a validation.

Bartender: I'm getting God-damned sick and tired of being responsible for the way everybody lives their lives!

Man: That's why you run a bar.

The bartender was complaining about his role as counselor, but the man reminded him that he should get used to it because it goes with the territory. 
Many who are alone and want to talk come in because they know their friends will be there, and if they don't know anyone, someone will be willing to talk anyway. As with any bar, people become more open and talkative when a few drinks have loosened their inhibitions. A comfortable social atmosphere is found in a "home territory" bar such as this.

\section{Entertainment}

Some drinking establishments place a greater emphasis on entertainment and "playing" at some activities than do others. Although this may not be as integral to the functioning of the "home territory" bar as to other types of bars, playing does exist and supplements rather than overshadows the social functioning within. Establishments which are primarily entertainment-oriented, such as those which have many pool tables or pinball machines or those which highlight loud music tend to have minimal social interaction, and what interaction does exist is usually dyadic. The entertainment in this "home territory" bar, includes contests, ritual events, films, games, live music, jukebox, singing, and television. These activities tend to involve groups of people, often those who were not previously well acquainted. Entertainment functions are not furnished to draw people into the bar (although this certainly is a factor) but instead as a "service" for the loyal patrons.

\section{Contests}

Several contests are periodically sponsored by and held inside the bar. One is the "Trivia Contest" which is open to anyone-who wants to enter. Questions are asked from categories characteristic of the older college student, such as "music from the $60 \mathrm{~s}-70 \mathrm{~s}$ " "Television" (from roughly the same time period), and "Sports." Contestants are gradually eliminated until a winner and runnersup can be determined and awarded small trophies. The "Spelling Bee" is organized similarly and conducted like any classic spelling bee.

The pinball machine may be construed as a type of contest because the person who scores the highest game during any given week wins a free pitcher of beer at the close of that period.

\section{Ritual Events}

An uncommon characteristic of some of the entertainment is its occurrence as a "ritual event." Many bars have occasional contests or special evenings, planned mostly to break the monotony and draw in newer, bigger crowds. But many of these special events happen only once each year.

The most important and widely-attended event in the "home territory" bar is the "Halloween Party," which is held on the Saturday night nearest to October 31st. About one week before the party, the bartender asks one patron, "Are you still coming as a gorilla?" and a regular at another table is asking several others, "Are you coming to the party? What are you coming as?" The biggest crowd of the year is present with as many people on the outside as those packed inside. Almost everyone wears an elaborate costume so the evening is spent trying to discover identities and drinking beer from the three free kegs. One long-time regular always takes "professional" movies of the party so most of those in costume take their turns becoming immortalized in a movie that will be shown each subsequent year. Topical events are represented, such as three people wearing Nixon masks a few years ago and more recently, lighted costumes representing the dangers of nuclear energy. Figures from current television shows and movies are always present.

Patrons seem to become and are treated like the characters of their costumes. The men in complete and convincing drag consistently act like women. One woman dressed like a belly dancer is being touched all evening by various men. Patrons seem to enjoy the temporary escape which costumes allow.

Another annual event is the participation in the downtown "St. Patrick's Day Parade." The bar is represented by the "AllIrish 3-D Marching Band" who carry a banner, dress in green, and wear 3-D cardboard glasses. This event is also filmed by the same male regular.

An event which occurs, after everyone returns to school in the Fall, is the "322nd Annual End-of-Summer Get Together and Be Someone Party," which is held in a nearby park on a Saturday afternoon. A free keg is provided for those playing softball, frisbee, or just sitting outside. 
Another party was initiated last year after problems with the bar's liquor license, which resulted in a temporary closure. Called the "1st Annual Second Coming Party," a free keg and reduced prices were offered throughout one evening. The object was to apologize for the inconvenience to customers and to advertise that the doors were once again open.

These annual events have continued while the ownership has changed, which suggests that it is the patrons, not necessarily the management, who request and support such activities.

Films

A full-sized twelve-foot screen which can be pulled down over one wall makes this establishment a movie theater on occasion. Presentations include anything from home movies to old television shows. A professor of French brought some films and slides of France one Friday afternoon and presented a travelogue to those students he had invited and anyone else who was interested.

The best films which draw a standing-room-only crowd are those of the "Halloween Parties." This almost-professional "home movie" is taken during the annual "Halloween Party" by one of the long-time regulars whose hobby is cinematography. To defray his costs, a jar on the bar has a sign on it which says "(his name) paid $\$ 130.00$ for the Halloween film-can you donate?" The films are from past parties in addition to the most recent one. It is evident that some of the patrons have been coming to this bar for a number of years because as a film of the 1976 party is shown, one man points to the screen, saying "That's me!" and others periodically yell, "There's Joe!" or."Look at-John then!" Certain faces in the film elicit applause and shouts. Before and after the Halloween movies, various other films are shown, including old cartoons, an espisode of the "Ozzie and Harriet" show complete with commercials, one of President Kennedy's speeches, and clips from the "St. Patrick's Day Parades." When everything has been shown, several customers loudly request, "Show the Halloween films again" and "Let's see the party again," but once is enough until next year.
Movies were shown more frequently than usual during the month of December. Flicks were shown during Friday evening and a feature film beginning at 5:00 p.m. on Saturdays. The advertisement which ran in the university newspaper presented the movies "Thru the courtesy of (filmmaker's name) Transactional Cinema Associations" and claimed "two projectors which sometimes work and without bothersome Dolby Sound. Phenomenological trips thru celluliod memorabilia. ..."

\section{Games}

Game playing necessitates a degree of closeness between friends, acquaintances, or strangers, which is readily provided by the "home territory" bar. Games allow two general barroom opportunities to be realized: sociability and playing, and allow a temporary escape from serious, goal-oriented everyday life.

The most often-played games are the pinball machines and electronic games. One striking difference between the players' behavior here and at the university is their tendency toward sharing one machine with several others. Although pinball machines ususally accommodate four players, they are commonly used by only one person at a time. At this establishment, however, the machines often have two, three, or four customers playing together. Sometimes they already know each other or one person simply places a quarter on the machine's glass top, saying, "I'm in the next game" or "My name's John Smith." The team effect could be due to the fewer number of pinball machines than are on campus, but it is more likely that those who patronize neighborhood bars are more accepting of closeness among strangers and less -fearful of appearing too forward when joining others at a machine.

Sometimes a group of customers will congregate at one table to play cards. When there are not enough players, one card-playing regular will often stand up and loudly ask, "Anyone play bridge? We need a fourth." Someone from another table will then join them and the game can proceed.

On warm days, a frisbee game might take place in the residential street adjacent to the bar or in the same gravel parking 


\section{Mid-American Review of Sociology}

lot which also serves as a site for outdoor drinking and potsmoking. One patron who was spending the afternoon in the parking lot commented, "You can't have frisbees without drugs."

\section{Live Music}

Singers perform two nights a week, beginning at nine and ending at midnight, closing time. An entertainer performs every Wednesday and every Saturday, each accompanying themselves on acoustic guitar. They play for donations to a usually-attentive crowd. Because of the regularity of each one's appearances, he too becomes a regular and the crowd is familiar with him. During the break he is like one of the patrons until he resumes his position on the makeshift stage in one corner of the room. After a slow song, the bartender shouts, "Play something fast!" and the singer obliges because his repertorie has no rigid order. A female regular goes from table to table with an empty beer pitcher repeating "donations" to each customer, who in turn deposits a dollar or so.

\section{Jukebox}

"Paperback Writer." "Mellow Yellow," "Eve of Destruction." It could be 1969 from the sound of the jukebox. Some newer records are available but the older "classics," including Mario Lanza's "Drink, Drink, Drink" are chosen most often. The jukebox is usually playing except when something important is happening, such as live music or films. One woman is going to each table saying "Collecting for the jukebox" and getting several quarters. Patrons are happy to oblige her for two reasons: first. because there-is no-worry that the money will be spent elsewhere and second, because it is more convenient to let her choose the music while they continue to socialize.

\section{Singing}

Singing by the patrons is not an organized facet of the enter tainment but rather a spontaneous response to musical acts, the. jukebox, or simply someone's suggestion. It is not common but does occur on occasion later in the evening. The one jukebox
The Campus Bar

song which will inevitably result in someone's singing is "Drink, Drink, Drink," which appears to be the bar's theme song.

One evening a group of strangers from one of the fraternities entered and began singing fraternity songs loudly and continually. This was regarded as inappropriate behavior by "outsiders" and in response several regular patrons left, with the remaining customers glaring. A small amount of singing is acceptable on occasion but too much is distracting and interferes with the social mingling which is important to most of the patrons.

\section{Television}

Televisions are found in many bars and may be played constantly. The television in the "home territory" bar is on as much as one might be in an average home-when there is nothing else to do or when something "important" is being broadcast. It often plays during the mid-afternoon when old situation-comedies are aired and when there are not many patrons with which to socialize. Important events warrant its use during the evening, such as a political report or a publicized sporting event. Field notes from an important event illustrate this point.

Eight people are seated around a large table directly in front of the wall-mounted television. The election returns are coming on for the 1980 presidential primaries. One man in his early $30 \mathrm{~s}$ shouts, 'All right, Reagan's got it again!' Several people at another table look startled and one says, "I never thought I'd hear that in (the name of the bar). What's happened to everybody?"

There is real concern that the pervasive conservatism of the $1980 \mathrm{~s}$ has even settled inside one of the last refuges for campus liberals. The T.V.'s volume is not turned up particularly loud, so those who wish to play the jukebox usually refrain for the benefit of those who want to watch and listen.

\section{Education-Orientation}

The distinct educational and intellectual overtones present are partially due to the fact this this home territory bar draws 
from a population with an educational orientation (the university). Other nearby campus bars are primarily recreational or for singles. The clientele here display a need to learn and to discuss intellectual issues in an informal meeting place related to the university, yet apart from it. Most patrons are involved with, or have been involved with the university, either as students or professors. This select but internally varied group makes it possible to realize several aspects of the bar's education-orientation: The "grapevine," or informal communicative network; learning through formal classes that meet here; learning informally from the presence of faculty or through supplementary materials; the study hall atmosphere; and the perpetuation of a "Last Radical Center."

\section{The Grapevine}

There is a "grapevine" present in the establishment. Near registration time students can be seen making their class schedules and asking," "Has anyone had Smith for History?" or approaching a group of English teachers and majors to find out the general content of a certain class.

Classes and professors are common topics of conversation for those students still in school or recently graduated. One who had been on campus for a number of years was telling a newer student, "Don't ever take Econ. 340," and later "Smith's kind of hard-1 got a C-but he's a really smart guy-if you want to work your butt off." Information is also relayed about events taking place on campus, such as the posters publicizing campus movies or customers simply talking about the new exhibit at the art museum.

This informal communication: network servas to inform regulars of the lessons or information that other regulars have learned regarding the functioning and offerings of the university.

\section{Classes}

Teachers who frequent this establishment sometimes bring all their students and hold class here instead of on campus, or students might bring a teacher. One Geology teaching assistant who occasionally frequents the bar held pre-test study sessions here and got a remarkable turnout. The ease with which classmates get to know each other surpasses that in campus classrooms, and the familiarity can be conducive to subsequent learning.
The owner is very receptive to classes meeting here because it insures that prospective customers will enter the establishment. In fact, he once said in response to a faculty member's intention to orally report on the establishment, "In the last week of school, you bring the whole class in and I'l supply them with free beer."

\section{Informal Learning}

Some objects and people in the bar directly facilitate learning and their presence indicates that some of the patrons seek out these aspects of the campus bar. The films that are occasionally shown can often be construed as educational, particularly the travelogues and the one of President Kennedy's speech. The maps on rollers behind the bar are usually referred to during a dispute over the location of some town. The following case illustrates this point.

Two men at the bar were talking about some fishing sites. One said, 'You know where $X$ is-about ten miles south of $Y$.' The other replied, 'No it's not-it's north of $Y$ :' After a few minutes the second man remembered the maps and asked the bartender to pull one down, and the matter was immediately settled.

Similarly, some of the university faculty come here with each other, with other friends, or with students. This serves to stimulate informal learning for some of the patrons. The nucleus of the Philosophy Department was coming every Friday afternoon for a while and some students would join them in discus sions of philosophy or any other topic. Professors are less guarded in this informal. setting and tend to be more candid. One was overheard while talking to a non-university social service professional saying, "That's the kind of shit they're always feeding people, that it's a sin to be selfish." Often more information can be gleaned while having a beer with one or two professors than during regular class periods.

Study Hall

If a student has some free time between classes and/or work, the person can go to the bar and study during the early afternoon hours when it is neither crowded nor noisy. The library 
may be too quiet and stuffy, with no allowance for drinking beer or openly smoking. Returning home can be distracting and often tempts one to go to sleep instead of studying.

The home territory bar may be the perfect study hall because of its informal atmosphere which can be conducive to some types of studying. It allows the customer to be alone while providing a comfortable feeling that others are around to socialize when the work is completed. This setting affords both privacy and security.

\section{The Last Radical Center}

Several regulars have referred to this establishment as the "Last Radical Center." Its patrons are largely the same people who, a decade ago, had obvious liberal attitudes toward politics and the war in Southeast Asia. Although the turbulence is gone, they still react to the world a little differently than do the young incoming freshmen. Some of the songs on the jukebox have a liberal aura about them, such as Barry McGuire's "Eve of Destruction" and Buffalo Springfield's "For What It's Worth."

Many patrons are around thirty years old and enjoy talking among themselves and to those who are younger about how different school and students were ten years ago. One regular has a term for friends he has known for a long time who were somewhat activist; they are the "warriors." The political posters on the walls and ceiling of the bar remind one that interest in the state of world affairs once fervently involved more students and professors than it does today. This setting perpetuates this radical philosophy.

\section{Sociation}

Talking among regulars is a primary activity in the home territory bar. This "sociation," the "form ... in which individuals grow together into units that satisfy their interests" is the founda tion of the home territory bar and integral to its continued func tioning (Wolff, 1950:41). Simmel uses this term in his analysis of the processes of group formation and the basic structure of society. Sociation is present in the home territory bar more often than in other types of drinking establishments because the patrons' common social identity (their university affiliation) and politically liberal outlook enhances conversation and friendship. In addition to small talk, there is a prevalence of serious conversation about politics, issues, and the state of the world. Not only do the topics of conversation make the home territory campus bar unique, but also the way sociation emerges. Patrons may occasionally relate to members of the opposite sex as possible pick-ups, but more often unisex relationships prevail. Sociation develops and becomes a bonding element among persons who frequent this establishment.

\section{Serious Conversation}

Campus bars contain intellectual components, and this bar has the additional liberal and socially-aware elements characteristic of the late 1960s and early 1970s. Discussing politics has always been common in bars, but here almost everyone has some input and supports it more by facts than passion. During the telecast of the presidential primaries, one regular looked up at the television and said, "We might have that asshole Reagan in the White House yet. He should have stayed in the movies." And a conversation ensued, including the politics which the other candidates were promoting. Reverend Jim Jones was a common issue of discussion after the Guyana mass-suicide, as was the seizure of the American hostages by Iranian students.

Topics relating to school are discussed more thoroughly and seriously here than in other campus bars. One group which includes a couple of faculty members has had several drawn-out debates on philosophical issues. Similarly, two music students had been talking about different instruments for nearly a halfhour: "I tried playing flute but I couldn't get the breathing down." "Yeah, I had trouble with the saxophone that way, then I took up trumpet and flugelhorn."

Advice and "counseling" are freely dispensed among patrons. Because of their age and school affiliation, many are in the process of joining the work force and assuming adult status. This transition causes much anxiety and it helps to talk to others who 
have already experienced it or who are also unsure that they are proceeding in the right direction. One older student said to a younger one,

It's not such a bad idea to stay at home. I got married right away, then divorced, and it's taken me eight years to get through school. I think you'll be happier waiting until grad school to move out.

Unisex Sociation

Compared to other types of drinking establishments, the ways which males and females relate to one another here can best be described as "unisex." Although there is not a complete elimination of gender distinctions among the patrons, it is more minimal than in the "meatmarket bar" or the male variety of local neighborhood bars.

Until recently, the restrooms had no clear distinguishing signs, and even now the men often use the women's restroom when their's is occupied. Both sexes mix freely: at the bar, at tables, and at the pinball machines. Females take their turns buying another pitcher for the table. Language is not "cleaned up" for women nor are they given any apparent special treat ment. They are not mistreated but rather treated equally. Equality is prevalent and it is almost as common to see one female greet another with a hug as for her to approach a male in the same way.

\section{Intimate Sociation}

Romantic encounters can begin here as they can in any other type of drinking or meeting establishment. The difference is that finding a prospective companion is a secondary function of the home territory bar. If a male and female meet and become roman tically involved in the home territory bar, it is usually due more to circumstances than to premeditated intentions.

Activity here is more often of a playful, flirtatious nature than serious propositioning. Because many of the patrons are regulars, their level of attachment is known and they are free to flirt without making any type of commitment. The bartender says to one male, "What are you doing here with the woman 1 love? After all, I saw her first." No one feels threatened or uncomfortable by this remark.

Members are quite open and feel free to say anything because others do not generally take offense; everyone is "just kidding." One regular was excited because he had just accepted a new job. He approached two women and said to one, kissing her hand, "I've never met you but I think I should. How are you?" She answered, "Better now," and he just smiled and left to join a group at another table. The female patrons are not passive recipients of this repartee. They are apt to greet a male customer with a hug or by throwing an arm around his shoulders. If either a male or female wants a relationship to proceed beyond the playful stage, it certainly can, but there is less pressure here than elsewhere for it to do so. In fact, many female customers feel like this bar is a "safe place" where they can come in alone and are not assumed to be looking for a man. One female regular was describing a male regular who deviated from this expectation: "He's the only one who ever hit on me... (the bartender) and I have an agreement where I just say I'm going home with him if anybody bothers me."

\section{Support Group}

The patrons of the home territory bar provide a support group for each other. Most of them have other reference groups as well, but for a few, the hard-core regulars, their primary social group is contained in this campus bar. There is a definite sense of "in-group" solidarity and cohesiveness here. The support group's function approaches that of an extended family. It is always there in good or bad times, and is always accepting and approving.

A distinct subculture can be said to exist here. This community of regular patrons displays a unique language, customs, values, and social norms, and comprise a distinct group of their own.

\section{In-Group Solidarity}

Regular patrons display a strong sense of identification and loyalty to other members and a feeling of exclusiveness toward 
non-members. This cohesiveness is usually done subtly as the following case illustrates.

At 10:30 p.m. a group of eight loud sorority and fraternity members came in, obviously for the first time because they kept pointing to the walls, saying, 'Look at that sign there' and 'Did you see that moose?' They began a beer-chugging contest among themselves, singing and laughing loud enough to disrupt conversations. Some regulars stared at them and said, 'Hey, why don't you quiet down' but when the outsiders were oblivious to these admonishments, other patrons just exchanged glances or left.

The core of regulars consists of a small number of people who patronize the bar regularly. Their frequent interaction allows them to know the bartenders and each other quite well, and promotes the emergence of trusting and loyal friendships.

\section{In-Group Cohesiveness}

A closed communication network provides for group cohesiveness. It informs members of absent members' whereabouts so they do not lose touch with one another. If someone is having a party and needs to find a patron whom he has not seen in a long time, someone in the bar will know where to find that person. Gossip and news is passed along: "Did you hear that Joe accepted a job in California?" or "Bill's finally getting a divorce." This network provides the thread of continuity between the past and the present, between the regulars who have stopped coming in temporarily or permanently, and those who remain.

The closed activities of the regulars add to the cohesiveness of the group. It is a group always ready to do something entertaining or relaxing. If customers want to play cards, they know whom to approach as a probable player. Several patrons like to play pinball against others instead of alone, so when they want to play, they turn to those at the table and say, "Anybody want to play a game of P-ball?" and two or three usually join them. One regular may wish to go to another bar or to a party, but wants to find some others to go along and suggests, "Why don't we go to the-___- for awhile" or "Joe's having a party tonight that should be a good one-three kegs." Similarly, regular patrons who were planning to attend a school activity later may all go together, such as an evening football game or a movie being shown on campus.

\section{The "Extended Family"}

The strongest aspect of the support group is its similarity to the extended family. The social intimacy of the regulars reminds one of relationships within a family unit. Members trust one another, and can leave their possessions unattended without worrying about them. lllicit drugs can be talked about without fear of someone reporting the conversation. Pitchers and glasses can be taken outside because the bartender knows they will be returned and not broken.

Accomplishments are shared with all the patrons, as is beer. One Friday afternoon the bartender interrupted all conversations with "Ladies and Gentlemen, I would like to present to you Mr. John Smith, who has just taken a job in Washington, D.C. for the United States Government." The other customers laughed and requested, "Speech, speech!" He continued, "Mr. Smith has also left a ten dollar bill up here by the cash register which he wishes us all to drink up," which was followed by applause. The bartenders also participate. If one is in a particularly good mood, it is likely that an occasional drink will be "on the house."

Like coming home, customers who have moved away always come back to visit this home territory bar. They can be assured that some of their old friends will be there on any given night, or at least someone will know where they can be reached. Unlike bars with transitory clientele, this one always has a few of the "old-timers" within easy access.

An ideal family always loves and supports its members through good and bad times. The customers here, especially the in-group regulars, are always accepted by the others. Unless a patron becomes violent or extremely obnoxious, he will be accepted, or at least tolerated. Although this is a predominantly 
white bar, the Black patrons are included and treated like everyone else. Allowances are made for the behavior of people who are extremely drunk or "wasted," and there is no discrimination against one physically handicapped patron who is very hard to understand.

\section{Sanctuary}

The home territory campus bar becomes a special place because of its patrons, especially the regulars who spend so much time there and develop a strong affinity for it. It meets many of their needs and serves various purposes for them. Taking this into consideration, it might be thought of as a sanctuary, a place of refuge and safety. The bar serves as a refuge for persons searching for help, relief, or escape. It is an asylum, offering safety and protection, and allows an escape from everyday stress and tension.

\section{A Home Away from Home}

The home territory campus bar provides a "home away from home." Along with member acceptance, most physical and intellectual comforts are provided for here: food, drink, tables, restrooms, television, music, games, books, and most importantly, companionship.

The number of telephone calls received indicates that friends of the patrons know where to find them. The bartender says "Hello Joe, how's the world treating you?" as Joe enters, and "Goodbye now. Have a good day" when he leaves, much as a host would treat a guest in his own house. Customers frequently return after having been out of town or circulation for-awhile because "I always come home when I'm in town."

\section{A Place to Relax}

It is easy to relax here because there are few or no demands on the person. Although different activities, conversations, and levels of involvement exist, no one is pressured to become a part. This contrasts with the recreational establishments where one would be out of place by choosing not to play mechanical or intimate games.
Here, if a customer feels like being alone in a crowd, he might sit at the end of the bar, away from the telephone. If he needs to study, he can. One regular patron slept at a table full of people throughout most of one evening and finally became alert enough to leave saying, "Thanks for letting me nod with you." The others understood why he was so sleepy and left him alone, watching his lighted cigarette so he did not burn himself with it when he fell asleep.

It is relaxing to just sit, drink beer, and talk with friends after a day at work or a day spent studying. "Finals week" is a popular time to visit the bar because students are adjusting to erratic test schedules and the stress of multiple exams. The completion of final exams usually calls for a celebration.

Female patrons are relieved to be able to go somewhere and talk only with each other, or with men without feeling as if they are being constantly sized-up and pressured into contributing more than conversation. Similarly, the bartender finds his job to be less consuming than in a "hard-sell," fast-moving bar where he would have little personal contact with the customers.

\section{A Safe House}

Relaxation is possible because one can escape the pressures that daily living guarantees. The home territory campus bar provides comfort to its patrons and as it continues to operate, it adapts to fit the unique population, or subculture it serves. An escape for one type of clientele might be disco dancing and cocktails, but here it is characterized by conversation, beer, music, and games. It is not a complete escape because the university ties are present, but it is still removed from the university because many patrons no longer attend and many hold the liberal beliefs and positions that are so rarely found on campus anymore.

One regular was talking about old times saying, "Do you remember when I got kicked out of the fraternity for wearing a black armband?" For him, this bar is an escape back to a time that was better and more exciting than the conservatism that is pervasive today. It appears that the bar itself, not just "getting out" or "getting away," provides the sought after escape because 
patrons tend to settle there once they arrive and do not typically just stop by while on a bar-hopping spree.

Escape to a safe place is necessary when jobs, families, and school cause personal stress and tension. Escape does not imply an inability to cope, but is simply a requisite for survival, much like sleep. A person may not necessarily need help, relief, or protec. tion, but it is comforting to know these are available and that a reliable group of patrons at a safe and comfortable neighborhood bar can provide them.

\section{CONCLUSION}

We have isolated a special and important variety of a campus drinking establishment, the home territory campus bar, and explored the supportive social functions that this setting provides for the larger academic community. Seven primary social functions were delineated from field observation and interview data of one such establishment over a 3-year period. These include: the provision of goods and services, the availability of entertainment, an education-orientation, the facilitation of sociation, the support group solidarity, a cohesiveness, and a place of sanctuary.

Of major importance is how this type of "bastard institution" is integrated into the broader academic environment. As one of the establishments that fringes the university, the home territory campus bar provides for some of the academic communities? physiological, psychological, and social needs in areas where the academic institution cannot or does not engage.

Colleges and universities undoubtedly are unable to provide for all members' needs thus, other supportive institutions are created to compensate for this deficiency. Some of these supportive institutions are recognized as legitimate and respectable while others, like bars, are considered disrespectable and their legitimacy is ignored. However, as we have shown, the home territory campus bar is of importance to the general well-being of the academic community.

This importance is clearly reflected in the number and variety of campus bars that fringe campuses throughout the country. Colleges and universities may learn and benefit from these "bastard institutions" as they attempt to meet their members' needs.

\section{REFERENCES}

Cavan, Sherri

1966 Liquor License. Chicago: Aldine.

Denzin, Norman K

1970 The Research Act. Chicago: Aldine.

Dumont, Matthew P.

1967 "Tavern Culture: The Sustenance of Homeless Men." American Journal of Orthopsy chiatry 37 (October):938-945.

Erdoes, Richard

1980 Saloons of the Old West. New York: Knopf.

Gottlieb, David

1957 "The Neighborhood Tavern and the Cocktal Lounge: A Study of Class Differences." American Journal of Sociology 62:559 562.

Hughes, Everett $C$.

1971 The Sociological Eye. Chicago: Aldine.

Macrory, Boyd E

1952 "The Tavern and the Community." Quarterly Journal of Studies on Alcohol 13:609-637.

Roebuck, Julian B, and Wolfgang Frese

1976 The Rendezvous. New York: The Free Press.

Webb, Eugene J., Campbell, Donald T.; Schwartz, Richard D., and Sechrist, Lee 1966 Unobtrusive Measures. Chicago: Rand McNally.

Wolff, Kurt H.

1950 The Sociology of Georg Simmel. New York: The Free Press. 